\title{
Adopting e-learning Facilities During COVID-19: Exploring Perspectives of Teachers Working in Indian Public-funded Elementary Schools
}

\author{
Arti Singh ${ }^{1}$, Kriti Gupta ${ }^{2 *}$ and Vivek Kumar Yadav ${ }^{3}$
}

\author{
Authors: \\ ${ }^{1}$ Dr. Arti Singh, Independent Researcher, New Delhi, India \\ ORCID iD: https://orcid.org/0000-0003-4463-0250 \\ 2 Kriti Gupta, Assistant Professor, Department of Psychology, J.P. College, Tilka Manjhi \\ Bhagalpur University, Bhagalpur, Bihar-853203, India \\ ORCID iD: https://orcid.org/0000-0003-3547-8437 \\ LinkedIn: https://www.linkedin.com/in/kriti-gupta-7b431293/ \\ Researchgate: https://www.researchgate.net/profile/Kriti_Gupta8 \\ ${ }^{3}$ Dr. Vivek Kumar Yadav, Independent Researcher, New Delhi, India
}

*Corresponding Author: Kriti Gupta (email: kriti.phs13@iitp.ac.in), Contact address- Assistant Professor, Department of Psychology, J.P. College, Tilka Manjhi, Bhagalpur University, Bhagalpur, Bihar-853203, India

Contributions: Dr. Arti Singh conceptualized and designed the study; Dr. Arti Singh, Kriti Gupta and Dr. Vivek were involved in data collection. Dr. Arti Singh and Kriti Gupta conducted formal analysis; Dr. Arti Singh prepared original draft; All authors contributed in writing, reviewing, editing and finalizing of the manuscript.

Acknowledgement: None

Funding: None

Total Word Count (excluding abstract): 5,652 


\begin{abstract}
The COVID-19 outbreak has led to an influx of research studies focusing on the new norm of online teaching-learning in higher education. However, much less is known about how this profound shift in pedagogy has impacted school education especially among rural children of India. The present study is an attempt to understand the barriers and challenges that teachers of Public-funded (PF) elementary schools face while teaching online. We developed a semistructured questionnaire and administered it on teachers of PF elementary schools in rural areas of Uttar Pradesh, India, using the online survey method. Thematic analysis of the responses we received $(\mathrm{N}=203)$ reveal five broad themes, namely physical environmental constraints, socioenvironmental limitations, parental support, issues of effective learning and health and wellbeing hazards. These findings have several implications for developing appropriate online teaching methods and making policy interventions to enhance learners' as well as educators' experiences.
\end{abstract}

Keywords: COVID-19, Public-funded schools, Online learning, Elementary school teachers, Rural India 


\section{Introduction}

On 23 March 2020, the Government of India (GOI) declared a nationwide lockdown to curb the spread of novel corona virus (COVID-19). Many people lost their means of earning due to lockdown; especially the daily wagers and the people running small businesses such as shopkeepers were economically more affected. The pandemic has also significantly impacted many sectors globally, including the education sector and lockdowns have led to a complete closure of all academic institutions worldwide (Sahu, 2020). Although GOI lifted the lockdown in June 2020, schools and colleges across the country still remain closed.

\section{School Education in India}

With an aim to improve the literacy rate of India, the Indian Constitution has provided for free elementary education (standards I-VIII) in all public-funded (PF) schools to children aged between 6 and14 years. According to the 2011 census, the literacy rate of India is $74.04 \%$ and an improvement in the dropout rate has also been reported (Educational Statistics at a Glance, 2016). Although both PF and private schools cater the educational needs of the country, $80 \%$

elementary schools in India are public-funded (DISE, 2015). It has also been observed that out of 320 million students, $84 \%$ live in the rural areas and of these, $70 \%$ attend PF schools (UNESCO, 2020). Despite being the only option for many families with a lower socioeconomic status or who belong to the lower castes, India's public education system is often criticized for being nonfunctioning and unproductive (India Today, 2020).

In recent years, GOI has implemented various measures to improve condition of the PF schools and to increase the enrolment rate of students from various socioeconomic statuses (MHRD, 2019). However, issues such as inadequate professional competencies in teachers, insufficient 
infrastructure, and lack of interest in digital learning seem to slowdown the government's plan to reform the education system in PF schools, specifically in rural India (Financial Express, 2018).

\section{Education During Pandemic}

Governments of various nations, including India, have directed their educational institutes to introduce remote teaching methods such as online learning and television learning (Varalakshmi \& Arunachalam, 2020) for students during the current pandemic. However, with a small proportion of Indians using the internet (Pew Research Center, 2018), the task of imparting education through a virtual platform has become daunting. Using online platforms for imparting education has affected many, but the most affected people are those who live in rural areas and have economic constraints. It is speculated that lockdown and the subsequent economic recession will adversely affect the dropout rate, especially among the poor (Alvi \& Gupta, 2020). Further, the online education system may also lead to the issues of mental health, especially among those who do not have facilities for online learning (Sahu, 2020).

\section{Rationale of the Study}

Growing interest in information and communication technology tools has already started changing the dynamics of classrooms and the role of a teacher in the classroom. Smart class and flipped classroom are some examples of this transformed pedagogy. However, most of the changes have been limited to higher education and private schools and in urban areas. Many of the PF schools lack basic infrastructure to use smart classes or utilize multimedia for teaching. Additionally, in many cases, principals and teachers of such schools are not trained to use projectors, tablets, digital interactive boards and apps for teaching. Most of the students and teachers are exposed only to conventional classrooms, or the 'chalk and talk' teaching method 
(Char \& Collier, 2015). This gap has become more visible during the pandemic as teachers and students are required to adopt the online teaching mode. Therefore, it becomes important to understand how educators are coping with the sudden need of remote teaching and what challenges they face, especially in the rural areas.

Uttar Pradesh (UP), the site of the present study is the India's is India's most populous and second largest state. Only $11 \%$ schools in UP have computer facility (Index of InternetReadiness of Indian States, 2016) and only 51\% schools have access to electricity (Oxfam India, 2020). Notably, UP is the second most power-deficient state of India (Central Electricity Authority, 2018). Thus, it can be expected that such a state of affairs could create hindrances in a successful delivery of education through online platforms.

In the present study, we explore the barriers and challenges of online teaching teachers of PF elementary schools in the rural areas of UP face. Findings of the current study would not only contribute in enriching the literature related to teachers' experiences of virtual classroom teaching in rural India during COVID-19, but also provide useful insights for developing online teaching methods and intervention programs for enhancing both teachers' and learners' experiences in the context of rural India.

\section{Method}

\section{Data Collection}

The aim of this study was to understand the problems and barriers of imparting education through online platforms from the perspective of PF elementary school teachers of rural India. This is a cross-sectional survey study carried out among teachers of rural areas of UP, India. We developed an online semi-structured questionnaire using Google Forms and appended a consent 
form along with the survey. Using purposive sampling, we approached teachers of PF elementary schools in rural UP who were known to either of the authors and shared the link of the questionnaire through WhatsApp, e-mail and Facebook. The participants were encouraged to either forward the survey form to other teachers with a similar profile known to them or to provide us their contacts details. The online survey was a brief, open-ended, two-item questionnaire and contained a few questions to get demographic information as well. The first open-ended question asked respondents to describe various barriers they are facing while teaching online. The second question asked for the barriers their students are facing in online learning.

This exploratory study was carried out from May 2020 to July 2020 and covered various districts of UP. We collected a total 229 responses. A check for missing data and eligibility criteria (teachers of PF rural elementary school of UP only) led us to discard 26 responses. Thus, for the final analysis we used responses of 203(114 or $56.15 \%$ female; 89 or $43.84 \%$ male) teachers. The age of the respondents ranged from 26 years to 57 years, with the mean age of 36.6 years. Further details about the participants are provided in Table $\mathbf{1}$.

\section{Table 1}

Demographic details of the study participants $(\mathrm{N}=203)$

\begin{tabular}{|l|l|l|}
\hline Variables & $N$ & $\%$ \\
\hline Age (mean=36.6) & & \\
21-30 & 41 & 20.19 \\
$31-40$ & 124 & 61.08 \\
$41-50$ & 26 & 12.80 \\
Above 50 & 12 & 05.91 \\
\hline Gender & & \\
Male & 89 & $43.84 \%$ \\
Female & 114 & $56.15 \%$ \\
\hline Religion & & \\
Hindu & 179 & 88.17 \\
Muslim & 21 & 10.34 \\
Other & 03 & 01.47 \\
\hline
\end{tabular}




\begin{tabular}{|l|l|l|}
\hline Marital Status & & \\
Married & 173 & 85.22 \\
Unmarried & 51 & 25.12 \\
Single/Divorce & 06 & 02.95 \\
\hline Educational Level & & \\
Graduation & 159 & 78.32 \\
Post graduation & 44 & 21.67 \\
\hline
\end{tabular}

\section{Data Analysis}

The survey elicited from the participants many comments on the perceived barriers of online learning. These responses were analysed with Braun and Clarke (2006) method of thematic analysis. Using the inductive approach, responses were initially coded for the themes independently and the coding scheme was discussed by both authors to resolve any differences. Once consensus was formed, we developed the themes.

\section{Findings}

The five themes we developed from our analysis are physical environmental constraints, socioenvironmental limitations, parental support, health and well-being hazards, and issues of effective learning. We examine these themes in detail in the next section. We also include some quotes from the teachers as examples of the respective themes.

\section{Physical Environmental Constraints}

Barriers in the form of physical environment were a prominent and recurring theme, and participants frequently mentioned its impact. Out of the 203 participants, 195 reported either one or more than one of the four physical environmental barriers, namely unavailability of smart 
phones/laptops, poor network, frequent power cuts and inability to recharge mobile data.

Unavailability of smart phones/laptops was the most cited barrier of online learning, followed by poor network connection. A participant mentioned:

90\% students in rural areas do not have smart phones or laptops. While the remaining $10 \%$ who own smart phones face other problems such as charging their smart phones due to frequent and long power cuts or they cannot afford renewal of data packs. (Male, 41years)

The problem of availability of smart phones/laptops is not limited to students only. Some teachers were forced to work on smart phones as they had only one laptop at home which their kids needed for their online classes.

Many participants reported slow internet speeds or poor network connection in rural areas as one of the many reasons of low interest in online learning. They also attributed to poor network the increase in their workload, as frequent network issues made the task of joining a class or uploading a video more difficult, time-consuming and tiresome.

\section{Socio-environmental Limitations}

The participants identified three socio-environmental constraints, namely work-life balance and limited study space for both themselves and their students and syncing online time with siblings for their students.

Many participants attributed an increased burden of household responsibilities and working hours to increased disharmony of their work-life balance. Notably, more female participants reported the issue of maintaining work-life balance (81females; 29 males).

Mentioning increase in the work, a participant commented: 
It takes extra 2 to 3 hours every day in making videos for my online classes. (Female, 28 years)

Doing all household chores is so tiresome that I am not able to give my $100 \%$ in the class and sometimes don't feel like handling quires of my students. (Female, 35 years)

According to some participants, many children were also facing the problem of increased household responsibilities, which led to frequent absenteeism. Female students were reported to face this problem more than male students.

To attend or teach an online class or to make a video for an online class, one requires a separate space with quite environment. However, our participants reported that securing such space proved to be a difficult task for them as well as for their students.

I make videos for [my] classes only when my three years old baby is asleep at night. To make videos you need a quiet environment. (Male, 34 years)

According to the participants, many students who are poor and/or live in a one- or two- room house face difficulties in paying attention to their online classes. Mentioning these problems students face, a participant said:

Due to space crunch at home, students have to attend classes on their roofs or sometimes under a tree. (Male, 52 years)

The problem of space aggravates when the students' siblings also have their classes at the same time. Talking about this issue, a teacher commented:

Clash of class timings with their siblings leads to many problems for students such as problem of space and problem of [using a] smart phone. (Female, 37 years)

\section{Parental Support}


Parents of a majority of students were either illiterate or just had a few years of schooling. According to many participants, due to this reason students get minimum or no parental support for their online studies. One of the major concerns of teachers was that since learning online is a new thing for students, they, especially the young children, are not able to handle it. However, things become worse for such students when they do not get any support from their parents also. A teacher commented:

Parents lack the technical knowledge regarding smart phones. They cannot even submit the homework of their children. (Female, 27 years)

Some participants further reported apathy of parents toward online learning. According to them, many parents consider online learning useless and do not actively help their children. As one participant commented,

Parents are afraid that their children will become addicted to mobile phones. (Male, 38 years)

This perceived mobile addiction leads parents to engage less with online class requirements and help their children.

\section{Issues of Effective Learning}

This theme revealed teachers' apprehensions regarding effective learning of students. Many of the participants reported inadequate attendance of students in virtual classrooms. They believed that many students are unable to join the class as they do not have smart devices. If students somehow manage to join, they would leave due to poor connectivity. As one of the teachers mentioned:

The network is so poor that sometimes we spend most of the allotted class-time in getting 
connected through the app. (Female, 43 years)

Those teachers who upload videos to tackle buffering issues expressed their concerns regarding keeping track of students' attention. For example, one participant said:

I don't know whether they pay attention to what I teach [through my video]. I try my best, but I cannot be sure if they have learned the topic. (Male, 46 years)

The participants also felt that they were unable to assess students' improvement accurately. Although, homework and assignments are given, they are not sure if the topic is well-understood in the first place. One participant said:

Performances of many students have decreased. Even those students, who earlier performed well, are now submitting mediocre work. (Female, 36 years)

Teachers were also worried about the quality of their interaction with students, as many reported student-side issues of poor concentration, less participation and maintaining discipline in a virtual class and teacher-side ones as the perceived inability to effectively teach science and mathematics and being unable to give more attention to weak students.

\section{Health and Well-being Hazards}

Many participants were concerned about the negative effects of online learning on health. The most frequent concern reported was of "effects on eyes" and "headache."Majority of participants attributed increased screen timings - due to online teaching - to their frequent headaches. Many of these participants were afraid that the continued use of small mobile screens and/or laptops may affect their sight as well as their students'. One participant said:

This mode [online teaching] is affecting my eyes badly and I have a headache every other day. 
(Female, 35 years)

Some participants also reported body ache due to increased sitting hours and lack of proper sitting arrangements at home. They shared similar concern for their students also:

Very few students have a study table and a chair at home. Some of my students complain of body ache due to improper seating arrangements. (Male, 28 years)

Students complain of hand ache also, due to continuous holding of phones. (Male, 38 years)

Respondents also revealed that many students do not have a smart phone and some of them face network issues. So, they gather at a common place, often at one of the friends' home, to attend classes together. Their parents discourage this as they believe that such gathering would expose their children to COVID-19 transmission. One participant said,

Some parents feel that if their child visits his/her friend's place [to attend online classes], it may expose them to COVID-19. (Female, 49 years)

Concern for their emotional well-being was also raised by participants. Many were worried about their students' mental and emotional well-being, as one participant said:

Some of my students have told me that they feel sad because they are not able to meet their friends in person. (Female, 33 years)

Another participant mentioned,

The actual classroom cannot be replaced with a virtual classroom. Students make bonds with other students and learn together in a real class. They are too young to develop virtual bonding. (Female, 52 years)

According to some participants, the requirement of smart phones and laptops has exposed many 
students to depression or anxiety over their financial status. A participant pointed out:

Some of my students feel really sad over their inability to buy a smart phone. (Female, 30 years)

Interestingly, some teachers were also worried about their emotional bonding with students over online classes. As one participant commented:

Emotional attachment is not there [in online classes]. (Female, 38 years) while another said, Students are unable to connect with us emotionally. (Female, 33)

\section{Discussion}

The aim of the present study was to identify the barriers of online teaching faced by teachers of PF elementary schools of rural UP. Teaching through an online platform has both advantages and limitations; however, in the context of a country like India, where one-fourth of the population is illiterate and more than one-third cannot afford three meals a day (The Week, 2019), introduction of online education may have many implications for both educators and learners. A major concern prevalent among most participants was physical environmental constraints of online learning such as lack of electricity, non-availability of laptops or smart phones, poor mobile networks and financial constraints in recharging for data packs. Participants argued that absence of basic infrastructure for online learning makes no sense of imparting education, as it may lead to knowledge disparity among haves and have-nots. According to a survey by National Council of Educational Research and Training, 27\% students of different central Government-aided schools have no access to smart phones and $28 \%$ students have to face the issue of frequent power cuts, making it the two most-faced barriers of online classes (Hindustan Times, 2020).

In another study, the percentage of students who did not have access to smart phones was estimated to be $56 \%$, while $12.02 \%$ students were said to have no access to any type of mobile 
phones (Indian Express, 2020).Although mobile devices are available to some of the students, living in rural and remote areas pose connectivity issues for them. Describing the plight of such students, various media reports have mentioned how students are compelled to climb their rooftops(The Hindu, 2020) or even hilltops (The Times of India, 2020) to reach a cellular network.

Some socio-environmental factors were also perceived as barriers for an effective delivery of online learning by our respondents. One such socio-environmental factor was difficulty in managing the work-life balance. Both male and female participants reported an increase in both paid and unpaid working hours and mentioned it as the cause of imbalance between their work and life. Furthermore, this dilution of boundaries between work and home has made their job more stressful, which has decreased their ability to provide adequate time and attention to their classes and students.

Various studies have explored difficulties faced by working men and women in maintaining a healthy balance between their work life and family life (Emslie \& Hunt, 2009). However, because ofCOVID-19, work from home (WFH)has become a new norm and led to a sharp rise in conflicts between work- and family life of the working people, especially of the female employees (Craig, 2020).

Even though there is no study on educators, it would be interesting to explore the challenges faced by them in maintaining their work-family balance with WFH in place. Highlighting her struggle of maintaining a healthy work-family balance, a female academic has commented, “...there is now a complete overlap in my life -no more hyphen or separation in 'work-family balance', and definitely no balance at all" (Boncori, 2020, p. 678). 
Interestingly, due to closure of schools, the issue of increased household chores among students was also reported by our participants. In an earlier study too students of an online program were found to face challenges in balancing their work, family and social lives (Parkes, Stein,\& Reading, 2014).However, we could not ascertain whether the students of our participating teachers also felt the same, as we did not have their first-hand accounts.

According to the participants, due to increased workload athome, many students, especially girl students, skip classes. The existing gender norms and the culture of preferring sons over daughters is one of the many causes of the overburdening of girl students with household chores and compelling the latter to drop school (Singh \& Mukherjee, 2018).Due to job loss, increased economic recession and financial constraints, it would be no surprise if in near future the rate of school dropouts, especially girl dropouts, among rural students increases dramatically in order to lower the household expenses.

Other than increased working hours as a barrier of effective online classes, participants also mentioned the problem of securing a separate space for their classes. As majority of Indians live in small houses (Times of India, 2008), space crunch is a common issue. To study or to conduct classes effectively, one needs to have a separate and a quiet space. However, according to the participants, as their kids also have virtual classes at the same time, it becomes difficult to get a separate space. Similar problem of space crunch faced by students was also mentioned. In majority of cases, as students' siblings also have classes at the same time, the issue of sharing space extends to sharing the mobile or laptop. Unfavourable study environment is one of the various hurdles of online education, as reported in a study on graduate and post-graduate students living in remote and marginalised areas of West Bengal, India (Kapasia et al., 2020).

Many other barriers to learning through online mode were identified by our participants. Some of 
these include students' low interest, low motivation, inability to understand their teachers' instructions, maintaining discipline during an online class, teachers' inability to give more attention to the weaker students, conducting fair tests and correction of students' copies.

Dhawan (2020) also suggested that students may find virtual classes boring and asserted that since 'online learning has so much of time and flexibility that students never find time to do it (pp. 8).' Technical difficulties in online learning (Favale et al., 2020) and inability of the learner to understand instructions by the teacher can inversely affect both student's and teacher's learning experiences though online education (Song et al., 2004).

Most of the teachers were worried about low attendance and the quality of education that students received through online platforms. As many participants argued that majority of schools in rural and remote areas are already suffering from low attendance rate (Deshpande \& Banerji, 2017; Gopal \& Bhaskar, 2017), this shift in the learning platform has pushed students to skip online classes. Further, as many such students are first learners in their family, they do not get any assistance from their parents in their studies. Studies have suggested that parents' educational level positively affects school achievement and negatively affects the dropout rate or poor attendance (Choudhary, 2006).Although, parental engagement in children's online classes is an understudied topic, it can be expected that parents would have a greater impact on online learning of their children (Liu et al., 2010, cited in Borup, Walters, \& Call-Cummings, 2019).

As parents' personal experiences are greatly influenced by the role demands of traditional schools (Hoover-Dempsey \& Sandler, 2005), they are unable to assess the importance of their role in their children's online learning (Waters \& Leong, 2014). Participants pointed out that parent of their students also perceive online learning as an inappropriate and ineffective learning tool. According to them, parents believe that online learning has extended their children's 
exposure to mobile devices and caused 'mobile addiction' among them.

A number of barriers in the form of health consequences of online learning were also identified. The use of computers, laptops and mobile phones has become part of our everyday requirement. However, their frequent use is often associated with various risk factors such as headache, blurred vision, and ocular congestion (Bogdănici, Săndulache, \& Nechita, 2017). Majority of participants reported a concern for their eyes due to continuous looking at mobile and laptop screens for making videos, correcting copies and delivering lectures. They also reported a similar concern for their students who they felt should have restricted screen timings only. Frequent headaches are another health consequence which they perceive is affecting them and therefore their ability to take online classes.

Participants also attributed frequent body ache to continuously working on gadgets. Working with a laptop requires an appropriate posture and safe distance from the screen; however, majority of users are not aware of various health issues their lack leads to (Wasnik \& Jeyakumar, 2016). Participants also attributed their body ache to inappropriate sitting arrangements at their homes.

The issue of physical discomfort due to prolonged use of mobiles and laptops was not limited to teachers only; many participants reported similar health consequences for their students also. Studies on students who use laptops for studying also report frequent physical discomfort due to its continuous usage (Das, 2012; Trimmel \& Bachmann, 2004).

Interestingly, some participants also mentioned an increased probability of COVID-19 spread due to online learning. They asserted that as majority of students do not have smart phones and face frequent network problem, they gather at one place for online classes. Teachers feared that 
such behaviour may expose them to corona virus. Although they wish to deter such gatherings, they could not do so because of limited options their students have.

Other than physical health consequence, some teachers also reported consequences in terms of well-being. According to them, students get no real-time interaction which gives more space for collaborative learning and emotional engagement. Moreover, a physical classroom is more likely to facilitate development of emotional support among students in the form of friendships and a healthy relationship with their teachers. It also helps in blurring the boundary between haves and have-nots. They also asserted that often the teacher's physical presence also works as a buffer against students' emotional distress.

Disaster leads to various psychological crises among both teachers and students (Di Pietro, 2017); however, it seems from our data that virtual boundaries in the form of compulsory online classes may accentuate these psychological crises. A few recent incidences of students' suicides because they could not afford an expensive smart phone or a laptop for their online classes (The Hindu, 2020) also exposes one of the dark sides of digital learning.

This study is not without a few limitations. First, our study sample consisted of teachers from a single state; therefore, our findings may not be the representative of problems faced by teachers of the other Indian states. Second, the generalization of the findings is also limited, as it specifically focuses rural setting. Inclusion of perspectives of teachers from urban and semiurban schools may have provided a broader understanding of the barriers of online learning. Third, although we have used open-ended questions, some participants did not give detailed responses either due to the small screen size of their smart phones or limited computer or internet skills. An interview-based study may have elicited richer responses and thus, in-depth understanding of the studied objective. 
Despite these limitations, our study has made some significant contributions. The main strength of the present study is that it provides an insight into the barriers of online learning among rural students. Majority of the studies have focused on the effect of COVID-19 on higher education. However, our study focuses solely on elementary education. Another contribution is that the present study highlights those barriers that one of the most vulnerable populations of Indian students encounter while learning online.

\section{Conclusion}

We investigated the challenges experienced by teachers in the aftermath of the lockdown while trying to continue teaching online in rural India and found that both teachers and students of government-funded elementary schools face various issues in using digital platforms. Along with some prevalent problems such as poor connectivity, physical health issues and emotional disturbance, the lack of support from parents and worries related to adequate learning as well as the spread of COVID-19 were also highlighted. Moreover, while switching from offline to online teaching mode during this pandemic, much less attention was paid to the financial constraints of the disadvantaged students from rural areas.

Since virtual classrooms and digital platforms have emerged as effective methods of teaching during this global pandemic, it is important to make them more inclusive. Based on our study, some pertinent measures to improve the effectiveness of online learning are suggested below:

- Instead of depending fully on the internet, other methods of remote teaching such as radio and television should also be explored. Although, GOI has dedicated some television and radio channels for airing lectures for students (Economic Times, 2020), there are no 
concrete instructions on how to include these radio and television teachings in regular online classes, especially for the schools in remote areas.

- As a large proportion of Indians is not tech-savvy, training parents and guardians (especially of elementary school going students') to use electronic devices is crucial as they can help young students in handling technology for their studies.

- There is an immediate need to improve the basic infrastructure: installation of more mobile towers in remote and rural areas as well as making available free wi-fi connectivity to students living in disadvantaged regions.

- The government should distribute smart phones to economically disadvantaged elementary school students with pre-loaded lectures for their classes.

- Researchers should design courses or develop study materials which can be taught when the popular tools of teaching are not available.

The outbreak of COVID-19 has not only hastened the digital revolution in educational system of remote Indian regions, it has also provided an opportunity to make teaching more learner-centric and to enhance the educator's competency and skills. Acknowledging challenges and barriers associated with technology-aided teaching and investigating solutions will have far-reaching benefits for the Indian educational system.

\section{References}


1. Educational Statistics at a Glance (2016). Ministry of Human Resource Development. Retrieved from https://www.mhrd.gov.in/sites/upload_files/mhrd/files/statistics/ESG2016_0.pdf

2. District Information System for Education (2015). Retrieved from http://dise.in/Downloads/Elementary-STRC-2015-16/Elementary$\underline{\text { State_Report_Cards_2015-16.pdf }}$

3. UNESCO. (2020). School closures caused by Coronavirus (Covid-19). Retrieved from from https://en.unesco.org/covid19/educationresponse

4. Challenges of rural students in India. (2020, July 22). India Today. https://www.indiatoday.in/education-today/featurephilia/story/challenges-of-rural$\underline{\text { students-in-india-1703143-2020-07-22 }}$

5. Ministry of Human Resource Development (2019). Retrieved from https://www.mhrd.gov.in/schemesschool

6. Singh, J. (2018, November 26). Why rural India still has poor access to quality education? Financial Express. Retrieved from https://www.financialexpress.com/education-2/why-rural-india-still-has-poor-access-toquality-education/1393555/

7. Varalakshmi R., Arunachalam K. (2020). COVID 2019 - role of faculty members to keep mental activeness of students. Asian Journal of Psychiatry, 51, 102091.doi: 10.1016/j.ajp.2020.102091. 
8. Poushter, J., Bishop, C. \& Chwe, H. (2018, June 19). Social Media Use Continues to Rise in Developing Countries but Plateaus Across Developed Ones. Pew Research Center. Retrieved from https://www.pewresearch.org/global/2018/06/19/social-media-usecontinues-to-rise-in-developing-countries-but-plateaus-across-developed-ones/

9. Alvi, M., \& Gupta, M. (2020). Learning in times of lockdown: how Covid-19 is affecting education and food security in India. Food Security, 12(4), 793-796.

10. Sahu P. (2020). Closure of universities due to coronavirus disease 2019 (COVID-19): impact on education and mental health of students and academic staff. Cureus. 2020;12(4):e7541. doi: 10.7759/cureus.7541

11. Sinha, B. (2020, July 01). Bypassing the Digital Divide. Oxfam India. Retrieved from https://www.oxfamindia.org/featuredstories/bypassing-digitaldivide\#: :text=In\%20UP\%2C\%20merely\%2051\%25\%20schools,state\%20have\%20a\%2 Ofunctional $\% 20$ computer.\&text=Lokmitra $\% 2 \mathrm{C} \% 20 \mathrm{Oxfam} \% 20$ India's $\% 20$ Raebareli $\% 2 \mathrm{D}$ based,ensure $\% 20$ classes $\% 20$ were $\% 20$ not $\% 20$ disrupted.

12. Central Electricity Authority (2018). Retrieved from http://cea.nic.in/reports/annual//gbr/lgbr-2018.pdf

13. Antony, N. J. (2019, August 17). Poverty Index: India rank 49. The Week. Retrieved from https://www.theweek.in/theweek/cover/2019/08/17/poverty-index-india-rank$\underline{49 . h t m l}$

14. Braun, V. \& Clarke V. (2006). Using thematic analysis in psychology. Qualitative Research in Psychology;3,77-101 
15. Hindustan Times (2020, August 20). At Least 27\% Students Do Not Have Access to Smartphones, Laptops for Online Classes: NCERT survey. Retrieved from https://www.hindustantimes.com/education/at-least-27-students-do-not-have-access-to$\underline{\text { smartphones-laptops-for-online-classes-ncert-survey/story- }}$ sp8nb0QZoBXXJ8ZsCLb3yJ.html

16. Indian Express (2020, June 13). About $56 \%$ of children have no access to smartphones for e-learning: study. Retrieved fromhttps://indianexpress.com/article/education/about56-pc-of-children-have-no-access-to-smartphones-for-e-learning-study-6457247/

17. Naha, A. L. (2020). Scaling New Heights to Attend Online Classes. The Hindu. Retrieved from https://www.thehindu.com/news/national/kerala/scaling-new-heights-toattend-online-classes/article31741780.ece

18. Time of India (2020, August 16). Students Climb Trees, Hills to attend Online Classes in Odisha: Minister. Retrieved from https://timesofindia.indiatimes.com/home/education/news/students-climb-trees-hills-toattend-online-classes-in-odisha-minister/articleshow/77571604.cms

19. Emslie, C., \& Hunt, K. (2009). 'Live to work' or 'work to live'? A qualitative study of gender and work-life balance among men and women in mid-life. Gender, Work \& Organization, 16(1), 151-172.

20. Craig, L. (2020). Coronavirus, domestic labour and care: Gendered roles locked down. Journal of Sociology, 1440783320942413. 
21. Boncori, I. (2020). The Never-ending Shift: A feminist reflection on living and organizing academic lives during the coronavirus pandemic. Gender, Work \& Organization, 27, 677-682.

22. Parkes, M., Stein, S., \& Reading, C. (2014). Student preparedness for university elearning environments. The Internet and Higher Education, 25, 1-10.

23. Singh, R., \& Mukherjee, P. (2018). 'Whatever she may study, she can’t escape from washing dishes': gender inequity in secondary education-evidence from a longitudinal study in India. Compare: A Journal of Comparative and International Education, 48(2), 262-280.

24. Kapasia, N., Paul, P., Roy, A., Saha, J., Zaveri, A., Mallick, R., ... \& Chouhan, P. (2020). Impact of lockdown on learning status of undergraduate and postgraduate students during COVID-19 pandemic in West Bengal, India. Children and Youth Services Review, 116, 105194.

25. Dhawan, S. (2020). Online learning: A panacea in the time of COVID-19 crisis. Journal of Educational Technology Systems, 49(1), 5-22.

26. Favale, T., Soro, F., Trevisan, M., Drago, I., \& Mellia, M. (2020). Campus traffic and eLearning during COVID-19 pandemic. Computer Networks, 176, 107290.

27. Song, L., Singleton, E. S., Hill, J. R., \& Koh, M. H. (2004). Improving online learning: Student perceptions of useful and challenging characteristics. The Internet and Higher Education, 7(1), 59-70. 
28. Choudhury, A. (2006). Revisiting dropouts: Old issues, fresh perspectives. Economic and Political Weekly, 5257-5263.

29. Liu et al., 2010, as cited in Borup, J., Walters, S., \& Call-Cummings, M. (2019).

Examining the complexities of parental engagement at an online charter high school: A narrative analysis approach. International Review of Research in Open and Distributed Learning, 20(1).

30. Hoover-Dempsey, K. V., \& Sandler, H. M. (1995). Parental involvement in children's education: Why does it make a difference? Teachers College Record, 97(2), 311-331.

31. Waters, L. H., \& Leong, P. (2014). Who is teaching? New roles for teachers and parents in cyber charter schools. Journal of Technology and Teacher Education, 22(1), 33-56.

32. Bogdănici, C. M., Săndulache, D. E., \& Nechita, C. A. (2017). Eyesight quality and computer vision syndrome. Romanian journal of ophthalmology, 61(2), 112.

33. Wasnik, P., \& Jeyakumar, A. (2016). Monitoring stress level parameters of frequent computer users. In 2016 International Conference on Communication and Signal Processing (ICCSP) (pp. 1753-1757). IEEE.

34. Trimmel, M., \& Bachmann, J. (2004). Cognitive, social, motivational and health aspects of students in laptop classrooms. Journal of Computer Assisted Learning, 20(2), 151-158.

35. Das, R. (2012). Occupational Health Concerns of Software Professionals and Their Coping Strategies. International Journal of Research Business Strategy, 1(1).

36. The Economic Times (2020, April 17). Education in time of COVID-19: DD, AIR will broadcast virtual classes through regional channels. Retrieved from 
https://economictimes.indiatimes.com/magazines/panache/education-in-time-of-covid-

19-dd-air-will-broadcast-virtual-classes-through-regional-

channels/articleshow/75200617.cms?from $=\mathrm{mdr}$ 